\title{
心理咨询理论与实践
}

\section{环境社会学视间下老年抑郁症的 干预个案研究}

\section{魏淑丽 * 姜路平}

滨州学院人文学院, 滨州, 256600

邮箱: wei3002@hotmail.com

摘 要: 人是环境中的人, 环境因素决定了人社会存在的状态。基于此, 本文 从社会学的角度对老年抑郁患者进行了个案干预和较长时间的跟踪调研。最终 发现通过一系列的社会因素的千预、环境的改变以及配合心理层面的关怀，老 年抑郁症有明显改善。并且在此基础上, 本文尝试构建了通过改善老年居住环境, 提升老年精神健康福祉的千预体系。

关键词: 环境社会学; 老年抑郁; 千预研究

收稿日期：2018-08-09; 录用日期：2018-09-01；发表日期：2019-05-15 


\title{
A Case Study of Intervention in Senile Depression from the Perspective of Environmental Sociology
}

\author{
Wei Shuli* Jiang Luping \\ College of Humanities, Binzhou University, Binzhou 256600
}

Abstract: People live in environments which determine the state of human existence in society. Based on this, this paper conducts case intervention and long-term tracking studies on elderly depressive patients from a sociological perspective. Finally, it is found that through a series of social intervention, environmental changes and psychological care, senile depression has been significantly improved. On this basis, this paper attempts to construct an intervention system to improve the mental health and well-being of the elderly by improving their living environment.

Key words: Environmental sociology; Senile depression; Intervention study

Received: 2018-08-09; Accepted: 2018-09-01; Published: 2019-05-15

Copyright (C) 2019 by author(s) and SciScan Publishing Limited.

This article is licensed under a Creative Commons Attribution-NonCommercial 4.0 International License.

https://creativecommons.org/licenses/by-nc/4.0/

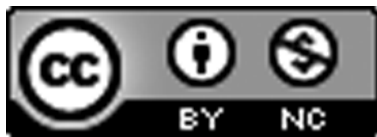

\section{1 研究目的与意义}

老年抑郁症是老年人常见的精神障碍之一。病因复杂，一般认为包含生理 层面、心理层面和社会层面的因素。在研究界, 关于老年抑郁的研究成果日渐 
增多, 但是大部分成果多见于综合医学层面, 其次是心理学层面的研究, 从社 会学层面的关注较少。深圳特区康宁医院精神科主任李东辉认为：“很多老年 人心理出现问题的症结就是觉得自己没有价值（没有尊严感），如果能让老人 积极融人社会，就会好很多，出现心理问题能及时发现干预就不会出现精神疾 病。”这实质是精神科医生在呼吁社会科学，特别是心理学和社会学更应该关 注老年人的精神健康问题。的确，精神健康不仅仅是一个医学领域的问题，更 是一个社会性的问题。一般认为精神愉悦是人身心健康的关键。人从根本上来 说是环境中的人，随着年龄的增加人的物理空间的活动半径在逐渐减小，对环 境的依赖性也越明显。因此，从某种意义上说环境因素与老年人的精神健康密 切相关。基于此，本研究拟从环境社会学视角下，通过改善环境因素，观察老 年抑郁患者的变化情况，分析环境干预对老年抑有症改善的意义。

\section{2 老年个案的基本情况与老年抑郁的社会因素分析}

\section{1 老年个案的基本情况}

2017 年春天，75 岁的李老太因为长期失眠，情绪低落到医院就诊后被确诊 为老年抑有症。生病之前李老太和丈夫生活在城市郊区的农村，虽然都有一些 慢性病需要长期服药，但身体状况基本稳定。他们育有 4 个子女，其中小儿子 和三女儿在离家不远的市区工作，一般每周末他们都会回家看望父母。另外 2 个女儿在外市工作。李老太查出病情以后，四个儿女都很着急，积极带老人到 处就医，但是基本以药物干预为主。

通过对话了解到李老太 2 岁时母亲早逝，10 岁时父亲去世，童年和少年严 重缺乏安全感。结婚后，虽然和丈夫的生活基本平稳，但是夫妻感情一般，李 老太经常埋怨丈夫不体贴，太自我。所以，李老太年轻时就把所有的希望都寄 托在子女身上。另外，据观察发现，李老太有严重的重男轻女思想。她虽然有 4 个孩子，但是最让她牵挂在意的就是她的小儿子。不过，总体上 4 个孩子深知 母亲年轻时不易，都很孝顺。另外，通过深人访谈，也了解到李老太性情较为 敏感，尤其被诊断为抑有症以后，更是担心周围人对自己病情的议论，导致失 眠情况加重。 


\section{2 从社会学角度深入剖析诱发抑有症的社会因素}

因为抑郁症的引发都有一定的社会诱因，在得知李老太有病后，4 个儿女积 极带她到本市和外市的大医院的精神科就诊, 在药物干预下病情稍稍平稳以后, 笔者开始尝试接触探知其内心深处的不安全感以及烦恼的根源。通过对话和观 察，笔者了解到引发其抑郁的诱因有以下几点：第一，老夫妻都有着严重的重 男轻女思想, 其小儿子于去年年底因为公司倒闭下岗, 其儿媳回家就经常在老 人面前抱怨，遂导致李老太过度的担心焦虑，这应该是一个重要的原因。因为 之前, 小儿子收人很高, 一直是老两口的骄傲。第二, 老两口年轻时虽然都是 民办教师，晚年国家有一定的补助，但是政府给予的补助很有限，并且因为都 患有慢性病，常年需要看医，也就是说老两口的生活虽然在经济上没有问题， 但是经济层面确实不够宽裕。第三，老两口夫妻情感较为淡漠，两个人基本没 有共同的话题和兴趣。性格外向的李老太经常感觉郁闷，多年来一直把情感更 多地寄托在子女身上。从社会学的角度来看, 这是一种典型的 “倒三角” 病理 性家庭结构。这种结构, 让从小缺乏安全感的李老太，在夫妻关系中得不到的 安全感, 全部寄托给了儿女。长期优秀的小儿子, 其实给了李老太很多的安全感。 但是小儿子近两年的失利，应该说是触动了李老太内心的严重不安全感。

\section{3 干预方法及干预过程}

\section{1 理论的可行性}

中国有 “橘生淮南则为橘, 橘生淮北则为枳” 的古话, 很清楚地反映了即 使是同一事物因为处在不同文化地域下也会形成完全不同的事物。这和 “生活 环境病” 有相似之处。老人可能对于 “生活习惯病” 的体验更为深刻。它是环境、 生活方式、表达方式、文化观念等的综合交织物。因而应该通过改善综合的环 境因素，提升老年人的精神福祉。

\section{2 干预过程}

根据上述理论视角，尝试采取的干预措施有：第一，根据老人重男轻女的 思想特点, 建议弟弟一家, 在老人面前报喜不报忧。改变以往与老人的互动方式。 
第二, 姐弟 4 人尽可能地放下工作，多陪母亲聊天，听她唠叨（宣泄与情绪释 放）。第三，努力积极寻医治疗（让她感受到子女的关心）。第四，咨询后了 解到李老太年轻时非常喜欢金银首饰，但是因为条件有限，很多愿望没能实现。 根据这些信息，遂建议 4 个子女在力所能及的情况下为老人去挑选一些首饰。 当儿女们将一些金银首饰给李老太的时候，很明显地能看得出李老太流露出一 些喜悦的表情。根据其女儿反映：“妈妈带上首饰还到村里要好的邻居家去， 让邻居看。”显然这种早期愿望的满足，对其病情的改善也是有一定帮助的。 根据环境社会学的意义，笔者建议其子女在力所能及的情况下，改善老人们的 居住环境, 即第五条。4 个子女集中购房, 装修好后劝说其父母到市内居住（据 了解，以前其母亲一直希望来城市居住，但是其父亲不同意，母亲为了迁就父 亲就一直住在农村）。这次和其父亲做了很长的沟通，他终于同意搬到市内来住。 笔者惊喜地发现从 2016 年 3 月李老太发病，到 2016 年 10 月 1 日两位老人来到 城市居住以后, 李老太的睡眠情况有了很大改善, 情绪基本看不出明显的抑郁了。 其中，笔者认为在众多干预措施中环境改善是极其重要的一条。因为前述，老 人性情敏感，在被诊断出老年抑郁症后，老人一直认为这是件丢人的事情，非 常在意别人的议论。当搬人城市社区以后，其实等于切断了老人来自农村社区 的一些不安全因素。相比较农村, 距离自己村庄不远的城市社区相对宽松包容 的环境，又完全相似的生活方式以及地方方言，让老人并不陌生，加之距离子 女物理空间更近，增加了老人的相对安全感。这与盛佳婉 (2013) 的研究也并 不矛盾 $[1]$ 。她在对中国发展最迅速的深圳市的调研中指出移民城市的老年人 （多为随子女移居的老年人）更容易抑郁焦虑。主要原因是，伴随社会转型加剧, 一部分老年人为了照看孙辈，或者老后在不得已的情况下选择背井离乡跟随远 在他乡的子女生活。但这种随子女移居的现象，与该案例环境改变的情况相比 有几个问题：第一，随子女移民的老人，在态度上是不得已的行为。如必须照 看孙辈; 不能自理了，必须依赖子女等，这在某种意义丧失了老人的主体性。 但是案例中的李老太在态度上是自愿的，且认为可以脱离乡村妇女对自己病情 的负面标签，是尊重了李老太的主体意识。第二，随子女移民的老人，往往距 离家乡较远，生活方式、方言等面临巨大挑战，而案例中的李老太是从市郊区 搬至市内，不存在生活方式与方言的问题。 
跟踪该案例，已经过去两年了，目前李老太 77 岁，虽然仍在服用药物，但 是抗抑郁的药物已经停止，仅仅服用一些助眠的药物，情绪基本稳定。当然， 以后可能仍有一些诱因会导致老年抑郁复发，但目前状况基本稳定。因而从某 种意义上说，从社会学的角度，结合一定的心理学知识，再配合药物干预老年 抑郁是有一定效果的。同时，也证实环境因素（人文关怀是其中的一部分）的 改善能够在一定程度上改善老年抑郁。根据需要以及老年人自身的经济条件, 可以考虑彻底改变老年人当前的居住环境。如果条件不允许，也可以考虑干预 老年人当前的居住环境。

\section{4 环境社会学视角下老年精神健康的干预体系构 建}

前述提到老年抑郁是环境、生活方式、表达方式、文化观念等的综合交织物。 因而应该通过改善综合的环境因素，提升老年人的精神福祉。另外，中国目前 的老年群体, 个性特质没有西方人那么鲜明, 整体与家庭成员的联系更密切一些, 情感的依赖性更强烈一些。

根据上述特点, 对于我国老年人精神福祉来说，重要的环境有微观的家庭环 境、中观的社区环境、宏观的社会环境（三者均包含制度、观念层的内容）。可 以从这三个层面来考虑如何通过改善、建构环境因素来改善老年人的抑有情绪。

第一，运用社会学的一些技巧对老年人重要的微观家庭环境进行干预：如 帮助家庭成员之间改善平素的沟通方式，增加对亲情的体验性和感受性; 为老 年人建立或拓展一些亲友支持系统，增加老年人的情感寄托以及使老年人获得 安心感; 教会老年人一些安全、快捷处理家庭事务的方法 (可以与老年社区工 作结合），以此增加老年人的自信心；科学了解老年人内心的不安全感因素， 努力帮助解决和消除 (一般认为不安全感和不自信是老年抑郁症患者共通的一 些心理特质）。

第二，对于老年人生活的社区环境进行改善或干预：社区环境是与老年人 生活密切相关的周边生活环境。对于老年人的观念、看法，以及邻里关系，交 往方式等也成为影响老年人精神健康的重要环境因素。比如邻里之间是否有自 觉尊重他人隐私的风气等。另外，可以考虑在社区中建立一支“青老年” “中 
老年”对于 “老老年” 的居家关怀义工队伍; 依托社区建立一些为老年人排忧 解闷的娱乐活动; 依托社区建立老年丧偶等同质性小组的互助活动; 建构具有 “平 等观念” 的社区教育（因为社会学有分层理论，这在中国的社会实践中表现也 很明显。老年群体因为老后收人差异较大, 存在一些低收人老年群体较为自卑, 不愿意参加一些社区活动，而这部分老年人更容易产生各种问题）［2］［3］。 如果短时间内社区环境干预不能见效的话，可以将老年案主在条件允许的情况 下, 转移社区。

第三，对于老年人所处的社会环境进行干预：社会环境看似宏观，但是对 于改善老年人精神福祉方面却是最重要的。因为人的烦恼大部分与文化、习惯、 制度有关。所以如何从提升老年人健康福祉的角度，影响改善宏观的社会环境 是很重要的。当然，这也是一个难点。因为人思想深处根深蒂固的一些观念的 改变是极其困难的，因而宏观社会环境的变迁是一个极其漫长的过程。比如说， 中国的一些老年人，现在伴随生活条件的提高，在文化上也渐渐地受西方的一 些个人主义文化的影响，在自己老了退休后很想好好旅游休闲放松一下身心， 同时又受传统文化的影响，纠结不能为子女照看孩子等，遂成为老年人的烦恼 之一。

\section{5 结语}

人是环境中的人，环境因素决定了人社会存在的状态。基于此，笔者从环 境社会学的角度对于一名老年抑郁患者进行了干预和跟踪调研。最终发现通过 一系列的社会因素的干预以及环境的改变（包括增加家人对老年人的关爱）， 对于老年抑有的改善有鲜明的效果。并且在此基础上，尝试构建了通过改善老 年居住环境，提升老年精神健康福祉的干预体系。

\section{基金项目}

滨州市社会科学研究项目 “乡村振兴背景下滨州农村互助幸福院养老模式 调研与对策” 的中期成果之一（项目编号：19-SKGH-44 )。 


\section{参考文献}

[1] 盛佳婉. 老年人精神健康不容忽视 [N]. 深圳特区报，2013-08-06.

[2]王晶.代际地位变动影响农村老年人精神健康 [N].中国社会科学报, 2013-10-11.

[3] 张霞, 杨一凡. 我国中老年人精神健康的影响因素研究 $[\mathrm{J}]$. 老龄科学研究, $2017,2$. 